\title{
Compact Reconfigurable Band Notched UWB Cylindrical Dielectric Resonator Antenna Using Single Varactor Diode
}

\author{
Ahmed S. Elkorany ${ }^{1 *}$, Sammar A. Saad ${ }^{1}$, Demyana A. Saleeb ${ }^{2}$ \\ ${ }^{1}$ Dept. of Electronics and Electrical Comm. Eng., Faculty of Electronic Engineering, Menouf 32952, Menoufia \\ University, Egypt \\ ${ }^{2}$ Faculty of Engineering, Kafr ElShiekh University Egypt \\ *corresponding author, E-mail :elkoranyahmed@yahoo.com
}

\begin{abstract}
This $\mathrm{p}$ aper $\mathrm{p}$ resents compact UWB $\mathrm{c}$ ylindrical $\mathrm{d}$ ielectric resonator antenna with reconfigurable band notch capability using single varactor diode. Theoretical results are achieved for the d esign with the range of frequencies 4-10.6 GHz. Using single varactor diode, different notch frequencies can be obtained using different capacitance values. The effect of changing the varactor position is al so ex amined. A Wide range of notch frequencies can be achieved using this simple configuration, which covers most of coexisted narrow b and systems. The notch frequency can be lower by increasing the capacitance value. Finite Element Method (FEM) and Finite Integration $\mathrm{T}$ echnique ( FIT) a re hired $\mathrm{t}$ o $\mathrm{s}$ imulate $\mathrm{t}$ he proposed a ntenna s tructure using H FSS and C ST M WS respectively. The n otch frequency co vers the $\mathrm{W}$ LAN $b$ and when $\mathrm{C}=0.9 \mathrm{pF}$ a nd c overs $\mathrm{t}$ he $\mathrm{W}$ iMAX $\mathrm{b}$ and when $\mathrm{t}$ he capacitance i s ch anged t o $0.8 \mathrm{pF}$ f or t he s ame an tenna configuration and varactor position. The antenna with DRA has a $\mathrm{d}$ irective $\mathrm{r}$ adiation $\mathrm{p}$ attern $\mathrm{i} \mathrm{nE}$-plane a nd omnidirectional $\mathrm{p}$ attern in $\mathrm{H}$-plane. A lso, the ga in $\mathrm{i} \mathrm{s}$ suppressed in $\mathrm{t}$ he no tched f requency. The gr oup d elay is nearly stable in the UWB frequency range, except at the notch frequencies
\end{abstract}

Keywords: Band no tch f requency, FEM, D RA, H FSS, micro strip, $\mathrm{U}$ WB, planar $\mathrm{m}$ onopole antenna, $\mathrm{T}$ unable, Numerical technique.

\section{Introduction}

Due to Federal Communications Commission (FCC) defined UWB between 3.1 - 10.6 GHz with a band width of $7.5 \mathrm{GHz}$ [1]. Hence, researchers have attracted for ultra-wide band $\mathrm{r}$ adio technology due to its a dvantages s uch a s highspeed data rate, low co st, s mall size, and more secure [2]. Planner monopole antenna is characterized by low cost, ease of $f$ abrication, lo $\mathrm{w} p$ rofile, wide $b$ andwidth, $a$ nd $h$ igh radiation e fficiency so th at it is o ne of the most common UWB an tennas [3]. A narrow band system as W LAN, WiMAX, a nd X -band are co existed i n t he same U WB frequency band. Recently a lot of UWB monopole antennas with single o $\mathrm{r}$ multiple no tch frequencies $\mathrm{t}$ o a void $\mathrm{t}$ his interference $h$ ave been $i$ ntroduced. The ba nd $n$ otch characteristics ca $\mathrm{n} b$ e ach ieved $\mathrm{t}$ hrough; various $\mathrm{s}$ lots i $\mathrm{n}$ radiating $p$ atch [4-7], s lots in feed line [8-10], s lots in the ground plane [11-13], and parasitic patches [14]. The wide range and UWB features achieved by the dielectric resonator antennas (DRAs) make them potential candidates for UWB systems [ 15]. S everal U WB D RAs with a b and-stop performance have be en pr oposed. Dielectric $r$ esonator antennas ( DRAs) ha ve s everal $f$ eatures, $i$ ncluding 1 ow dissipation loss, high radiation efficiency, various excitation mechanisms, different DR shapes, nearly constant gain, and compact a ntenna s ize [ 16]. It has more s hapes s uch as cylindrical [17], r ectangular [18], hemispherical [19], a nd cylindrical $r$ ing [20]. H owever, these a ntennas ha ve fixed band $\mathrm{n}$ otch $\mathrm{c}$ haracteristics a nd in cas es where there is no interference, they ar e $u$ nable to utilize the al 1 o ver U WB frequency $r$ ange. $\mathrm{H}$ ence, $\mathrm{u}$ sing $\mathrm{r}$ econfigurable $\mathrm{b}$ and no tch structure can improve the performance of the UWB system. In reconfigurable band no tch UWB a ntennas, changing the notch frequency is achieved by using lumped elements such as PIN diodes or varactor diodes [21-22].

Our goal in this paper, to achi eve a simple reconfigurable $\mathrm{b}$ and no tch $\mathrm{U} \mathrm{WB}$ a ntenna using cylindrical DRA. A slot is made on feed line to be loaded by single varactor d iode. A w ide $\mathrm{r}$ ange of frequency band-notches, which cover almost all the narrow band coexistence systems, can be obtained simply by changing the capacitance value and position. A variable capacitor or a varactor diode instead of using single capacitor element can do reconfiguration. Finite element method (FEM) in the frequency domain and finite integration technique (FIT) in the time domain are us ed to simulate the proposed structures using Ansys HFSS [23] and CST MWS [24], respectively. The proposed antenna with a directive $\mathrm{r}$ adiation $\mathrm{p}$ attern i $\mathrm{n} \mathrm{E}$-plane a nd o mnidirectional pattern in H-plane. Also, the gain is suppressed in the notched frequencies. The group delay is the almost flat response is noticed over the operating bandwidth, which indicated very little distortion sharply in the notch frequency. These results 
suggest that the proposed a ntenna will be us eful widely in UWB applications.

\section{Antenna design}

The pr oposed c ylindrical D RA monopole a ntenna structure is s hown in Fig. 1 . The a ntenna is p rinted on a $n$ RO3003 dielectric substrate having a thickness of $0.75 \mathrm{~mm}$ with a relative permittivity of 3 . Where the total size of the antenna is $\mathrm{W}_{\mathrm{a}}, \mathrm{L}_{\mathrm{a}}$. The ground plane which is on the back side with $\mathrm{W}_{\mathrm{a}}, \mathrm{L}$ width and length respectively. Cylindrical DRA with radius $R$ and height $h$. Rectangular slot with length $S$ is made i $\mathrm{n} t$ he micro $\mathrm{s}$ trip line $\mathrm{t}$ o $\mathrm{f}$ it a varactor $\mathrm{d}$ iode. A $\mathrm{n}$ SMV2019-040LF varactor from $0.3 \mathrm{pF}$ to $1.4 \mathrm{pF}$ depending on the ap plied $\mathrm{r}$ everse $\mathrm{D} \mathrm{C}$ voltage. The $\mathrm{v}$ aractor has two different p ositions a s s hown in Fig. 1. All this parameter shows in table1.

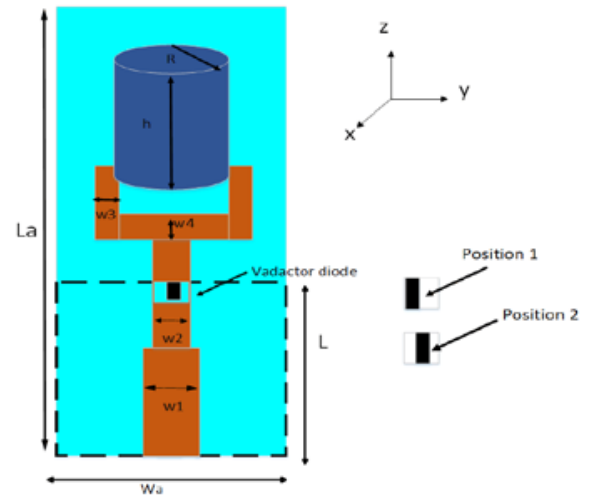

Figure 1: cylindrical DRA shaped UWB planar monopole antenna loaded by a single varactor diode.

Table 1: The design parameters of the proposed antenna

\begin{tabular}{c|c}
\hline Design parameters & Dimensions in $(\mathrm{mm})$ \\
\hline$W_{a}$ & 12 \\
$L_{a}$ & 30 \\
$w_{1}$ & 1.95 \\
$w_{2}$ & 1.7 \\
$R$ & 3.6 \\
$S$ & 1.5 \\
$H$ & 10 \\
$w_{3}$ & 1.3 \\
$w_{4}$ & 1.1 \\
$L$ & 9.5 \\
\hline
\end{tabular}

\section{Results and discussion}

In the beginning, the cylindrical DRA shape is optimized to ach ieve UWB characteristic the reflection c oefficient is examined. Figure 2 shows the reflection coefficient $S_{11}$ with different $E_{\mathrm{r}}$. As $\mathrm{E}_{\mathrm{r}}$ decreases, the antenna has wide band width and a $\mathrm{n}$ ull is found between 4 and $9 \mathrm{GHz}$. At $\mathrm{E}_{\mathrm{r}}=13$ the antenna s et the U WB ch aracteristics a nd has a c ontinuous bandwidth between 4 and 10.6 GHz. Figure 3 demonstrates the effect of dielectric length on the reflection coefficient. As shown in fig3. decreasing the dielectric length, increasing the antenna band width beyond $11 \mathrm{GHz}$. Figure 4 ill ustrates the effect of dielectric radius on reflection coefficient. It is clear that when $\mathrm{R}=3.6 \mathrm{~mm} \mathrm{t}$ his a chieving $\mathrm{U}$ WB c haracteristic. Figure 5 demonstrates $t$ he e ffect of gr ound 1 ength o $\mathrm{n} t$ he reflection co efficient. It is cl ear that when $\mathrm{L}=9.5 \mathrm{~mm}$ this achieving $U \mathrm{WB}$ ch aracteristic. A s ingle varactor $\mathrm{d}$ iode is loaded in the slot. The varactor position is changed two times as $\mathrm{s}$ hown in $\mathrm{F}$ ig. 5 In each $\mathrm{p}$ osition, the cap acitance is changed an $\mathrm{d} t$ he co rresponding $r$ eflection co efficient $i \mathrm{~s}$ stored. Figures 6-7 show the return loss versus frequency for the different capacitance values and position. In each position increasing $\mathrm{t}$ he cap acitance $\mathrm{v}$ alue, $\mathrm{d}$ ecreasing $\mathrm{t}$ he notch frequency. A wide range of notch frequencies can be obtained using this simple configuration, which covers m ost of the narrow band coexistence systems. For example, as shown in Figure 5 the notch frequency covers the WLAN band when $\mathrm{C}=0.8 \mathrm{pF}$. CST and HFSS are used and their results are shown in $\mathrm{F}$ ig. 8. V ery good ag reement is o btained b etween b oth results

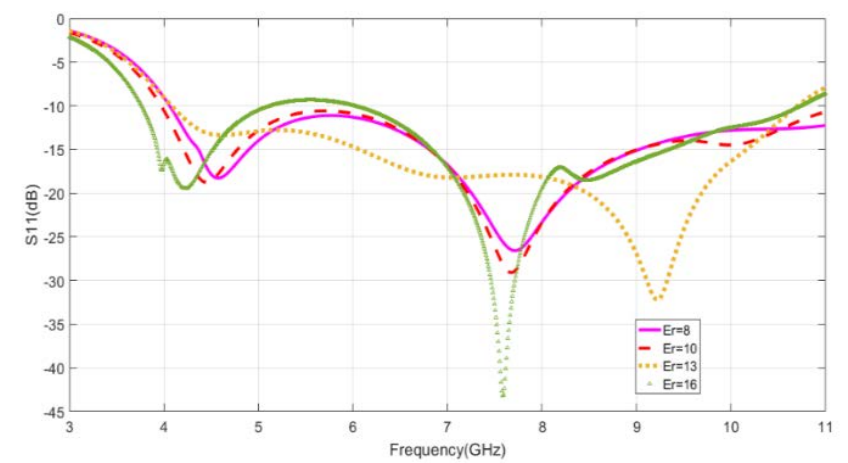

Figure2: Simulated $\mathrm{S}_{11}$ characteristics of the proposed UWB cylindrical DRA monopole antenna without slots for different $\mathrm{E}$

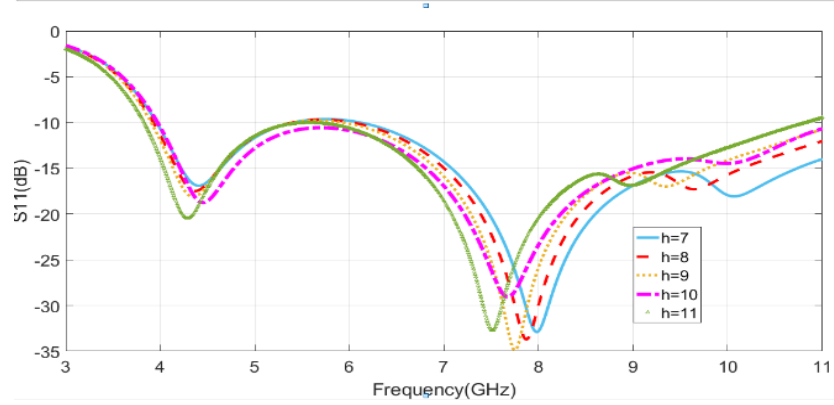

Figure3: Simulated reflection coefficient for variousl ength of DRA $h$. 


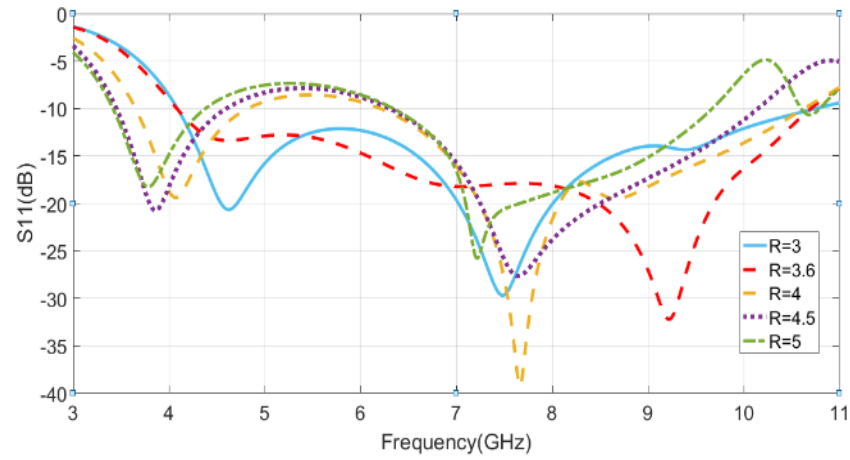

Figure4: Simulated reflection coefficient for various radius of DRA

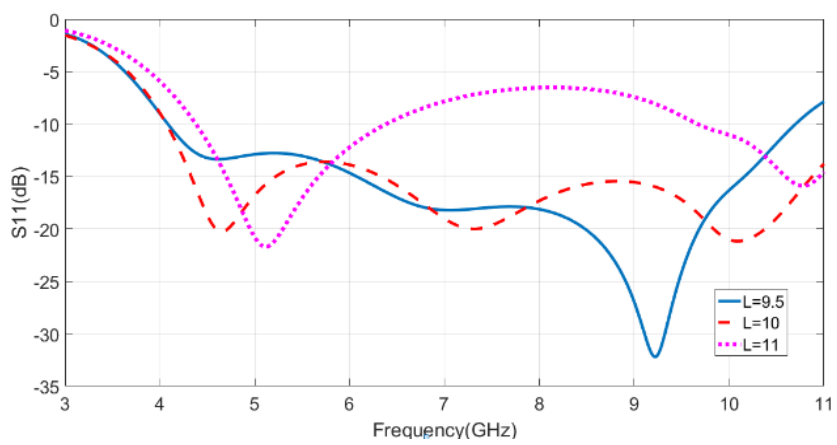

Figure5: Simulated reflection coefficient for variousl ength of ground $\mathrm{L}$.

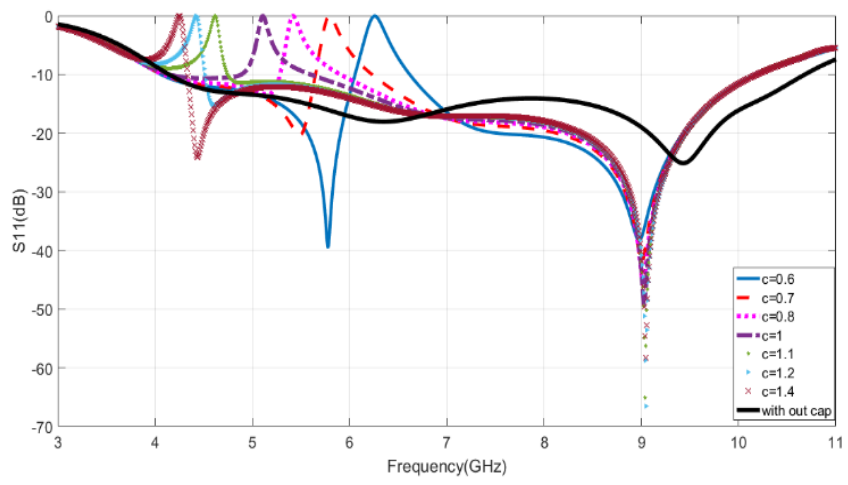

Figure 6: $\mathrm{S}_{11}$ characteristics of the proposed antenna for different capacitance values in position one

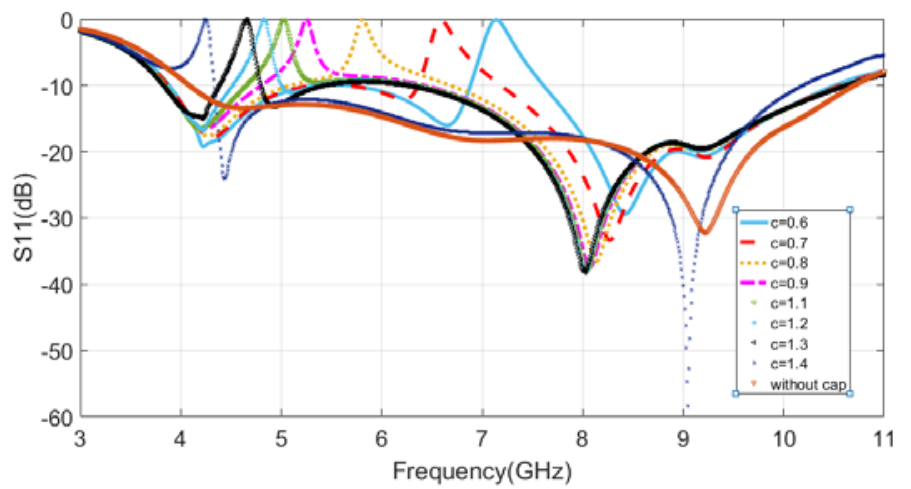

Figure 7: $\mathrm{S}_{11}$ characteristics of the proposed antenna for different capacitance values in position two

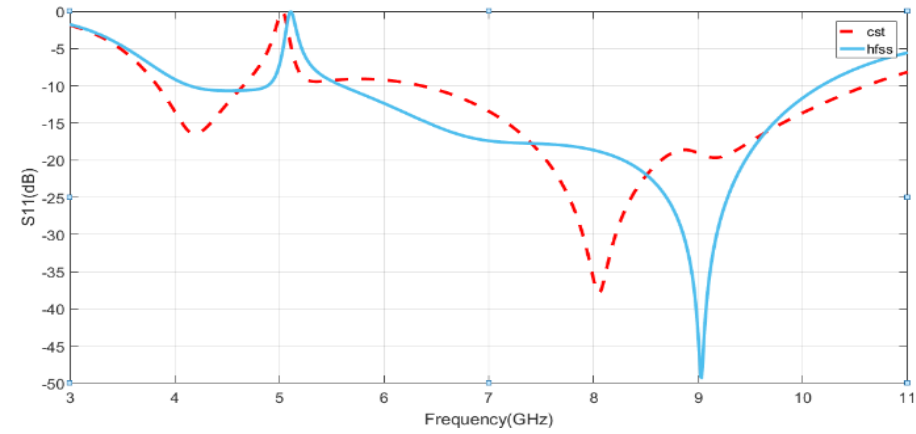

Figure8: The simulated S11 of the proposed antenna with $\mathrm{c}=1 \mathrm{pf}$ using $\mathrm{CST}$ and HFSS

\section{THE RADIATIONS PATTERNS, GAIN, and GROUP DELAY}

In this section, the radiation pattern gains, and group delay for the Previously stated cases will be achieved. Figure 9 shows the different radiation pattern at different frequencies $4,6,10 \mathrm{GHz}$ for the proposed antenna with capacitors elements. From figure, it's clear the pattern is directive in the E-plane and omnidirectional in H-plane. The gain is shown in fig.10. AS shown in figure, the gain is suppressed in the notched frequencies at $5.2 \mathrm{GHz}$ for given capacitor value. The group delay is shown in Figure 11. The group delay has very little variations across the operating band within a range of $1 \mathrm{~ns}$, but at the notch frequency, the group delay has very sharp changes.
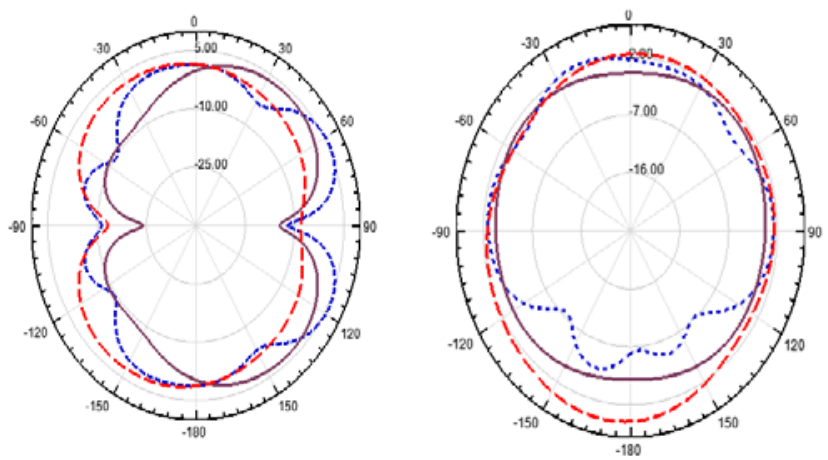

Figure 9: The Radiation patterns of the UWB antenna cylindrical DRA with capacitor elements. $\mathrm{C}=1 \mathrm{pF}[4 \mathrm{GHz}$ (Red-long dashes), $6 \mathrm{GHz}$ (Blue-short dases), $10 \mathrm{GHz}$ (brown -solid)]

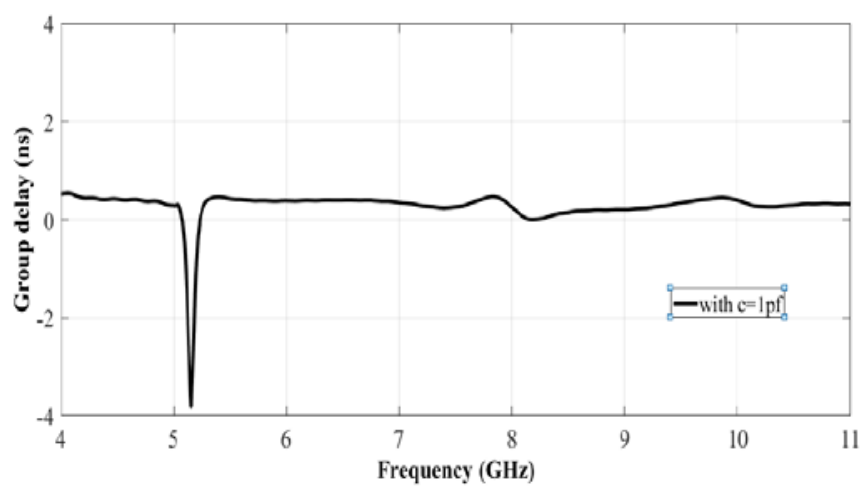

Figure 10: The proposed antenna gain versus frequency. 


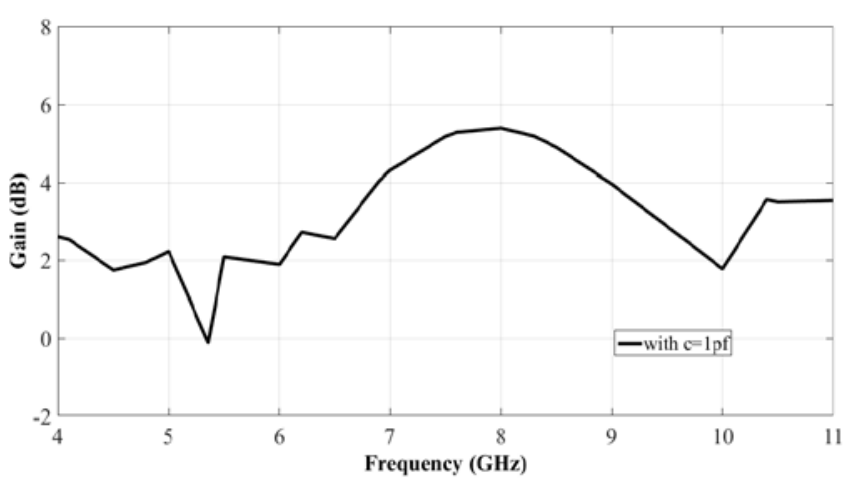

Figure 11: The group delay.

\section{Conclusion}

In $\mathrm{t}$ his paper, $\mathrm{ul}$ tra-wide band a ntenna $\mathrm{w}$ ith $\mathrm{s}$ ingle ba nd notched characteristics has been proposed and analyzed. The UWB antenna is examined on substrate RO3003 with relative permittivity of 3 and has cylindrical DRA radiation patch. Different notch frequencies can be obtained through make a rectangular slot on micro strip and loaded by varactor to achieve tunable notch frequencies. A wide range of notch frequencies $\mathrm{c}$ an be obtained using this simple c onfiguration, which covers most of the narrow band coexistence systems. The effect of the capacitance $\mathrm{v}$ alue of $\mathrm{t}$ he $\mathrm{v}$ aractor $\mathrm{d}$ iode o $\mathrm{n}$ the $\mathrm{n}$ otch f requency is investigated. FEM is used to simulate the proposed antenna structure using ANSYS HFSS. The not ch frequency covers the WLAN band when $\mathrm{C}=(0.8-1) \mathrm{pf}$. The proposed antenna yields a directive radiation pattern in the E-plane omnidirectional the pattern in H-plane. Also, the gain is suppressed in the notch frequency

\section{REFERENCES}

[1] F. YANG AND Y. R. SAMIL, MICRO STRIP ANTENNAS INTEGRATED WITH ELECTROMAGNETIC BAND-GAP (EBG) STRUCTURES: LOWMUTUALCOUPLING DESIGN FOR ARRAY APPLICATIONS," IEEE TRANSACTIONS ON ANTENNAS AND PropagATION, VOL. 51, NO. 10, PP. 2936-2946,2003

[2] H.-Y. Lai, Z.-Y. Lei, Y.-J. Xie, G.-L. Ning, and K. Yang, UWB an tenna with dual $b$ and rejection for W LAN/WIMAX bands u sing CSRRs, Progress in E lectromagnetics Research Letters, Vol. 26, 69-78, 2011.

[3] C.-C. Lin, H .-R. C huang, A $3-12$ G Hz U WB pl anar triangular monopole antenna with ridged ground-plane, Progress in E lectromagnetics R esearch Letters, pp.307-321, 2008.

[4] Y. T. L o, D . S olomon a nd W. F . R ichards, T heory and Experiment on $\mathrm{M}$ icro $\mathrm{S}$ trip A ntennas, IEEE T ransactions o $\mathrm{n}$ Antennas and Propagation, Vol. A p-27, no. 2, pp. 137-145, 1997.

[5] G. L. Ning, K. Yang, H. Y. Lai, Y. J. Xie, and Z. Y. Lei, UWB Antenna with Dual Band Rejection for WLAN/WIMAX Bands U sing CS RRs, IEEE T ransactions o $\mathrm{n}$ Antennas and Propagation, Vol.26, pp 69-78, 2011.

[6] M. G. Roozbahani, A. A. Kalteh and R. Fallahi, A novel UWB Elliptical Slot Antenna with Band Notch Characteristics,
Progress i n E lectromagnetics R esearch, P IER 8 2, p p 1 27136,2008.

[7] J. Choi, J. Jung, K. Chung and W. Choi, Compact UltraWideband Printed Antenna with Band-Rejection Characteristic, Electronics Letters, Vol.41, no.18, pp124-126,2005.

[8] J. W. J ang, H. Y . H wang, An I mproved B and-Rejection UWB A ntenna with $\mathrm{R}$ esonant $\mathrm{P}$ atches a nd Aslot, IEEE Transactions on Antennas a nd P ropagation, V ol. 8, pp. 299$302,2009$.

[9] C. A. Fernandes, J. R. Costa and C. R. Medeiros, Compact Tapered S lot U WB A ntenna with W LAN B and R ejection, IEEE Transactions o $\mathrm{n}$ Antennas a nd $\mathrm{P}$ ropagation, $\mathrm{V}$ ol. 8 , pp.661-664,2009.

[10] J. W. Lee, J. Kim and C. S. Cho,5.2 GHz Notched UltraWideband Antenna Using Slot-Type SRR, Electronics Letters, Vol. 42, no. 6,2006.

[11] K. Bahadori and Y. R. Samii, A Miniaturized Elliptic-Card UWB A ntenna with W LAN B and R ejection $\mathrm{f}$ or $\mathrm{W}$ ireless Communications, IEEE $\mathrm{T}$ ransactions o $\mathrm{n}$ Antennas a nd Propagation, Vol.55, no.11, pp 3326-3332,2007.

[12] F. Zhu, A.A. Alhameed and J. Xu, Multiple Band Notched UWB Antenna with Band Rejected Elements Integrated in the Feed Line, IEEE Transactions on Antennas and Propagation, Vol. 61, no. 8, pp 3952-3959,2013.

[13] K. H. Kim, S. O. Park, S. H. Hwang and Y. J. Cho, BandNotched UWB Planar Monopole Antenna with Two Parasitic Patches, Electronics Letters, Vol. 41, no. 14, 2005.

[14] M. V. Jacob, J. Mazierska, M. E. Bialkowski and A. M. Abbosh, A P lanar U WB Antenna with $\mathrm{S}$ ignal $\mathrm{R}$ ejection Capability in th e 4-6 GHz B and, IEEE Mi crowave O ptical Techniques Letters, Vol.16, no.5, pp 278-280,2006.

[15] A.W. Glisson, D. Kajfez and J. James, Evaluation of modes in $\mathrm{d}$ ielectric $\mathrm{r}$ esonators $\mathrm{u}$ sing a $\mathrm{s}$ urface $\mathrm{i}$ ntegral eq uation formulation, IEEETransactions Microwave Theory Tech., Vol. MTT-31, pp. 1023-1029, 1983.

[16] D. Kajfez, A. W. Glisson and J. James, Computed modal field distributions for isolated dielectric resonators, IEEE Trans. Microwave Theory Tech., Vol.MTT-32, pp. 1609-1616, 1984.

[17] Y. F. Wang, T.A. Denidni, Q. S. Zeng and G. Wei, Bandnotched UWB rectangular d ielectric resonator antenna, Electronics Letters, V ol. $50 \mathrm{~N}$ o. 7 pp. 48 3-484, 27 th M arch 2014.

[18] B. Mukherjee, V. Dinesh Kumar and M. Gupta, A novel Hemispherical D ielectric Resonator Antenna o $n$ an Electromagnetic B and Gap substrate for broadband and high gain systems, Vol .86, pp.11185-1190,2014.

[19] G. Drossos, Wu, and L. E. Davis, THEORETICAL AND EXPERIMENTALINVESTIGATIONOF CYLINDRICALDIELECTRIC R ESONATOR ANTENNAS, 
IEEE Transactions Microwave Theory Tech. V ol. 13, No. 3 , 1996.

[20] M. Abedian, S. K. A. Rahim, Sh. Danesh, S. Hakimi, L. Y. Cheong, and M. H. Jamaluddin," Novel Design with DualBand-Rejection Characteristicsfor WiMAX/WLAN Bands, IEEE ANTENNAS AND WIRELESS PROPAGATION

LETTERS, VOL. 14, 2015

[21] Wu, W., Y.-B. Li, R.-Y. Wu, C.-B. Shi, a nd T.-J. Cui, Band-Notched U WB A ntenna with $\mathrm{S}$ witchable an $\mathrm{d} T$ unable Performance, I nternational J ournal o f A ntennas and Propagation, Hindawi Publishing Corporation, 2016.

[22] L i, Y . an d R . M ittra, Tunable an d R econfigurable Frequency Rejection $\mathrm{C}$ ircular S lot A ntenna $f$ or $\mathrm{U}$ WB Communication Applications, PIERS Proceedings, 1583-1587, Prague, Czech Republic, July 6-9, 2015.

[23]http://www.ansys.com/Products/Electronics/ANSYSHFSS

[24] https://www.cst.com/products/cstmws. 